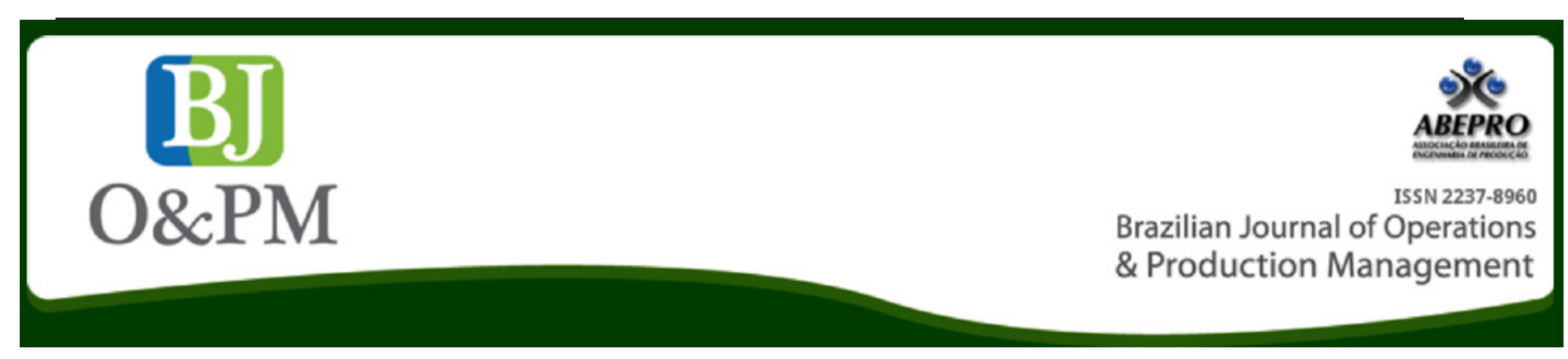

\title{
INFLUENCY OF CUTTING TOOL'S ANGLE ON MILLING OF COMPOSITE MATERIALS PERFORMED BY ROBOTS
}

\author{
José Otávio Savazzi ; Gustavo Franco Barbosab \\ a University of Sao Paulo (USP) - Sao Carlos, SP, Brazil \\ ${ }^{b}$ Federal University of Sao Carlos (UFSCar)- Sao Carlos, SP, Brazil
}

\section{ABSTRAC}

Purpose: This work aims to present an evaluation of the composite materials during the milling process performed by robots regarding the cutting parameters and tools applied to different conditions. An evaluation of the robot behavior is analyzed when the cutting tool's angles are changed.

Approach: This paper provides a contribution related to the reduction of forces in robot axis during the milling of composite materials associated to the forces involved during the process that can reduce the lifetime of the robot.

Design: It has been used a polar robot integrated with a motor spindle to perform the milling on nomex honeycomb material. Results are presented for a better understanding of the process and as a source of data for any new robotized solution development.

Originality: Despite looking like a common analysis in the milling area, it has still incipient research approaches related to machining of aerospace composite materials by robots.

Methodology: Consists in milling trials of composite material and the comparison of two methods of tool entry, the Straight Plunge and Ramping-in.

Findings: Analyses on joint 5 of the robot regarding the efforts on it. Comparison between data of two strategies used for entry and exit of the tool in material during the milling process, the straight plunge and the ramping-in.

Research implications: New developments in composite milling are urgently needed to improve the performance of the process, useful tools' life, a better quality of the final product and avoidance of damages on machines. The challenges are to achieve the optimum integration point of all process parameters in order to reduce operation costs.

Practical implications: The paper provides a starting point for the development of methods to identifying better ways for milling of composite materials. In this context, this work contributes to improvement of the quality and cycles times beyond to get more reliability and productivity for the business, besides how to do a better entry and exit in the composite avoiding damages on robots and wear of tools. All benefits of this new research are shown on a case study of an industrial example.

Keywords: Robot; Composite Materials; Milling: Cutting tool; Automation. 


\section{INTRODUCTION}

In today's aircraft manufacturing processes, several new features make machining operations very challenging according to production requirements. Parts are made of thin or thick multi-material stacks with a large scope to cover and complex assembly sequences. In addition, the current ramp-up in aircraft programs involves improving productivity while keeping process quality and reliability.

The use of composite materials in aerospace and automotive applications has been and will continue to grow at a very high rate due to the high strength and low weight of the materials (Sorbo et Dionne, 2014).

These materials are the base of any aircraft furniture and one of the components that provide greater differentiation to a business jet compared to other aircraft is the furniture.

Furniture must provide comfort, quality, exclusivity, luxuriousness and refinement, eminently superior, to meet customer demands, implying the use of automated systems developed specifically to meet these needs specified in the projects (Costa, 2009)

On this way, new techniques to process those materials have been developed in order to reach better conditions in term of fabrication, tools and process parameters. All efforts drive toward to increase productivity, reduction of costs, quality improvement and innovation.

\section{LITERATURE REVIEW}

The aircraft industry has been now optimizing their technical manufacturing approaches in order to match the new aircraft specifications for composite and mixed materials.

The manufacturing of aircraft components is based primarily on mechanizing a manual process. This fragment is confusing and I couldn't understand what you meant through it. Automated solutions using robots can cover today's requirements and be capable to support programs and new products in the future.

\subsection{Composite Materials}

The rapidly expanding applications of composites in the recent past have provided much optimism for the future of our technology. Although man-made composites have existed for thousands of years, the high technology of composites has evolved in the aerospace industry only in the last twenty years. Filament-wound pressure vessels using glass fibers were the first strength critical application for modern composites. After these, boron filaments were developed in the 1960's, which started many US Air Force programs to promote aircraft structures made of composites. The F-111 horizontal stabilizer was the first flight-worthy composite component (Tsai, 2008).
Modern aircrafts show a high ratio of composite parts in their structure. In the Airbus A350 and Boeing 787 more than $50 \%$ of the materials used are composites (Figure 1 and Figure 2).

Therefore the need for automation processes in CFRP manufacturing becomes visible (Apmann et al., 2012).
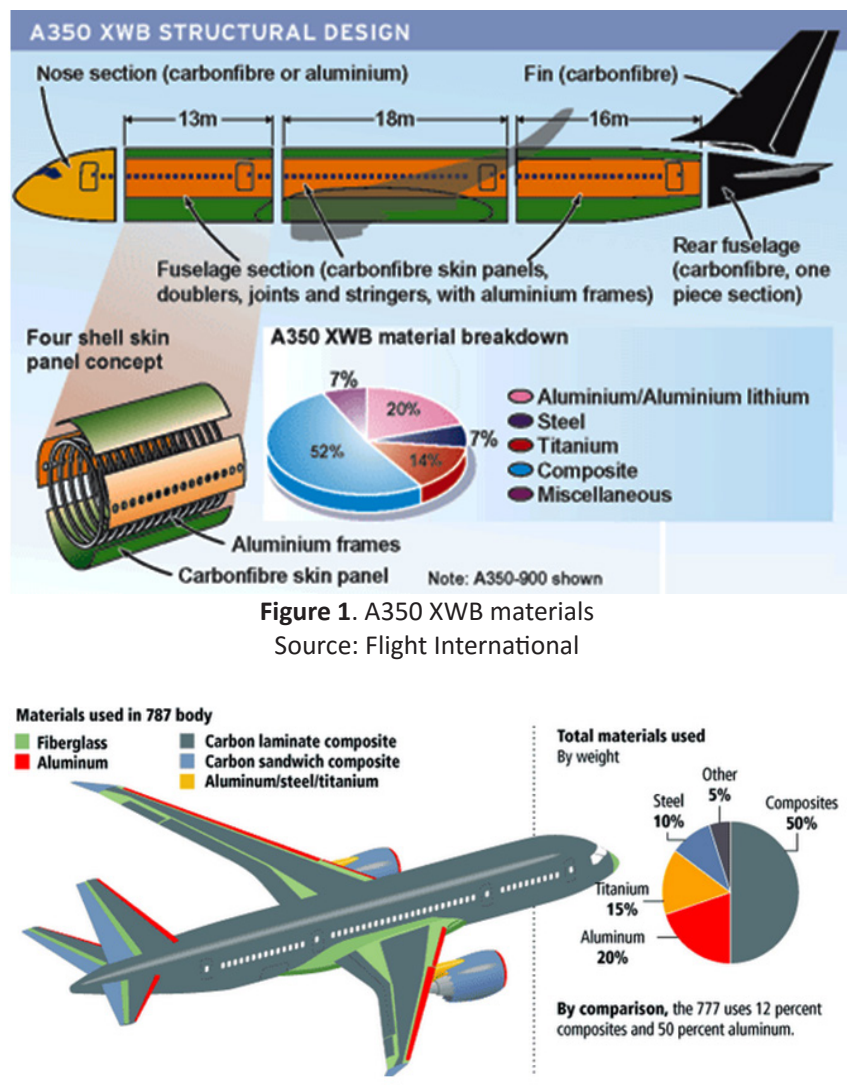

Figure 2. Comparison between B777 and B787 Source: Aviation beta (2015).

The use of composite materials brings a whole host of benefits such as greater fuel efficiency, reduced cabin noise, increased cabin humidity and a lower cabin altitude. However, there were many problems associated with the use of carbon fibre at the start of the design process, and tests after tests had to be carried out to ensure that the B787 was safe to fly (Science in the News, 2012).

On the other segment, business jet uses a lot of composite material for manufacturing of its furniture. Into this market business, the furniture plays a key role and the materials used in its fabrication should provide a high differentiation aesthetic, tactile and other subjective requirements of perception, in addition to meet the basic technical requirements of engineering and aeronautical regulations (Bushnell, 2006).

In business jets, the furniture is an item of extreme importance that must present customized features and is associated with affinity, sense of satisfaction and comfort in 
the owners and passengers. The furniture of business jets consists of partitions, kitchens, closets, toilets, wardrobes, seats, tables, sofas, shelves, sinks, side edges and consoles, among other components (Lyon, 1997).

Figure 3 shows an example of business jet furniture set regarding toilet and closet of a kitchen.

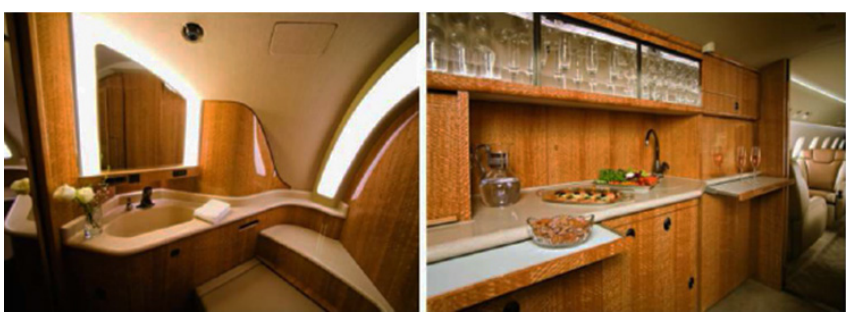

Figure3. Toilet and Closet

Source: Barbosa et al. (2015)

\subsection{Milling Process}

According to Groover (2010), milling is a machining operation in which a work part is fed past a rotating cylindrical tool with multiple cutting edges, as illustrated in Figure 4. The axis of rotation of the cutting tool is perpendicular to the direction of feed. This orientation between the tool axis and the feed direction is one of the features that distinguish milling from drilling. In drilling, the cutting tool is fed in a direction parallel to its axis of rotation. The cutting tool in milling is called a milling cutter and the cutting edges are called teeth.
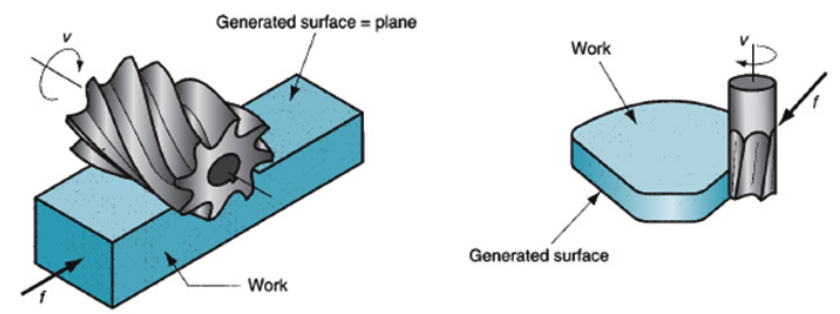

Figure 4. Milling process

Source: Groover (2010)

The geometric form created by milling is a plane surface. Other work geometries can be created either by means of the cutter path or the cutter shape. Owing to the variety of shapes possible and its high production rates, milling is one of the most versatile and widely used machining operations. Milling is an interrupted cutting operation; the teeth of the milling cutter enter and exit the work during each revolution. This interrupted cutting action subjects the teeth to a cycle of impact force and thermal shock on every rotation. The tool material and cutter geometry must be designed to withstand these conditions.

\subsection{Automation by robots}

Automation can be defined as the technology by which a process or procedure is performed without human assistance. Humans may be present as observers or even participants, but the process itself operates under its own self-direction. Automation is implemented by means of a control system that executes a program of instructions. To automate a process, power is required to operate the control system and to drive the process itself (Groover, 2010).

As indicated above, an automated system consists of three basic components: (1) power, (2) a program of instructions, and (3) a control system to carry out the instructions.

The relationship among these components is shown in Figure 5.

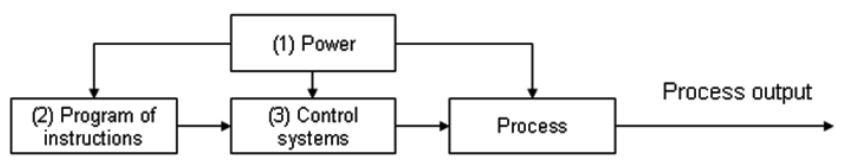

Figure 5. Elements of an automated system Source: Groover (2010)

An industrial robot is a general-purpose programmable machine possessing certain anthropomorphic features. The most obvious anthropomorphic, or human-like, feature is the robot's mechanical arm, or manipulator.

The control unit for a modern industrial robot is a computer that can be programmed to execute rather sophisticated subroutines, thus providing the robot with an intelligence that sometimes seems almost human.

The robot's manipulator, combined with a high-level controller, allows an industrial robot to perform a variety of tasks such as loading and unloading production machine, spot welding, and spray painting.

Robots are typically used as substitutes for human workers in these tasks. The first industrial robot was installed in a diecasting operation at Ford Motor Company. The robot's job was to unload die-castings from the die-casting machine.

Robot anatomy is concerned with the mechanical manipulator and its construction.

The Figure 6 shows a configuration of one of a popular 6 axis industrial robot.

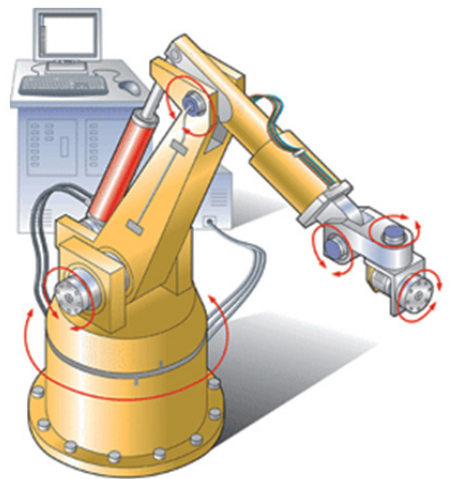

Figure 6. Industrial Robot configuration 11 Source: Controle e Automação Industrial (2014). 
An industrial robot consists of a mechanical manipulator and a controller to move it and perform other related functions. The controller unit consists of electronic hardware and software to operate the joints in a coordinated fashion to execute the programmed work cycle.

Day by day, aircraft manufacturers have been implementing several robots on their different manufacturing processes. Figure 7 shows an example of it.

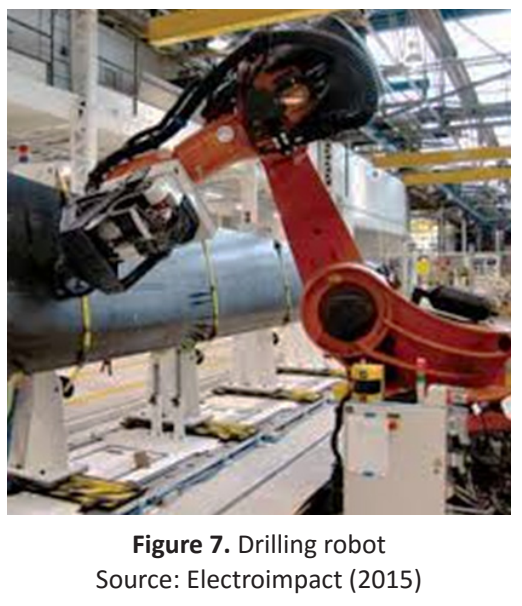

\section{ROBOTIZED MILLING OF COMPOSITES}

Based on an integrated milling system that uses robots for manufacturing of business jets primary parts [8] that mill grooves for a finishing application and drilling of holes on sandwich panels.

This paper provides a contribution related to the reduction of forces in robot axis (joint 5) regarding the entry and exit when milling composite material, mainly when special tools are used.

A diamond coated tool (showed in Figure 8 ) is used to mill ' $T$ ' grooves in composite materials, the tool has a large area, which cause an excessive force $(F=P . A)$ in the joint 5 of the robot, during the entry of the tool in composite plate.

Where: $P=$ pressure, $A=$ Area.

The diameter (D) of the T tool is $25 \mathrm{~mm}$. Thus, the tool's circular area $(A)$ is $\sim 491 \mathrm{~mm} 2$.

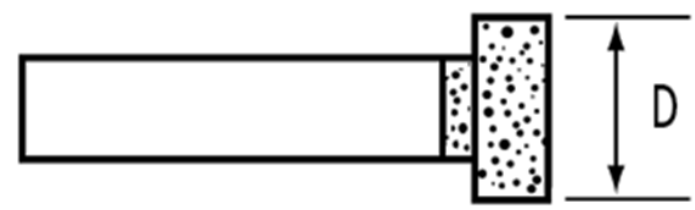

Figure 8. Diamond coated tool.

Incorporated in the system, a $100 \mathrm{~kg}$ payload Fanuc Robot $\mathrm{R}-1000 \mathrm{iA} / 100 \mathrm{~F}$ is equipped with a HSD high-speed spindle End-effector to perform the milling process.
This full integrated system is able to perform the milling on composite materials. On this application, sandwich panels are used as primary parts

Figure 9 below show this integration.

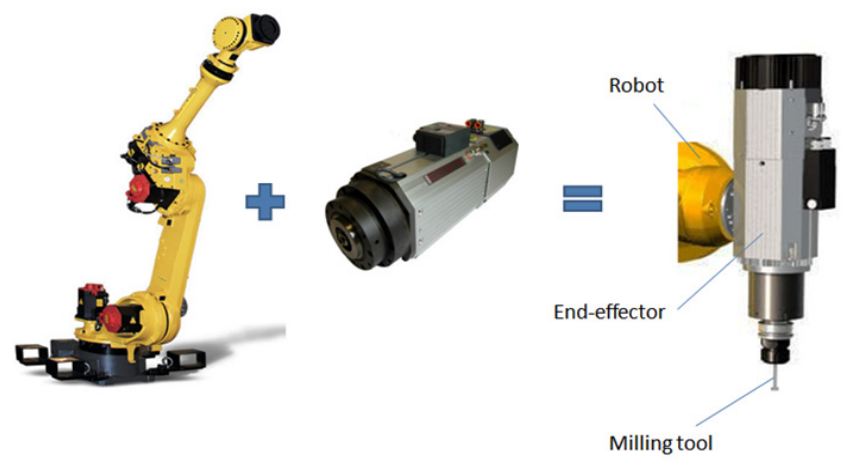

Figure 9. Robot and End-effector.

So, this integration showed above is used to milling a kind of composite material called sandwich structure.

Laminated structure with a core center is called a sandwich structure.

Laminate construction is strong and stiff, but heavy. The sandwich laminate is equal in strength, and its weight is much less and less weight is very important to aerospace products. The core of a laminate can be made from nearly anything. The decision is normally based on use, strength, and fabricating methods to be used (AvStop, 2015).

Various types of cores for laminated structures include rigid foam, wood, metal or the aerospace preference of honeycomb made from paper, nomex, carbon, fiberglass or metal (AvStop, 2015).

Figure 10 shows a typical sandwich structure.

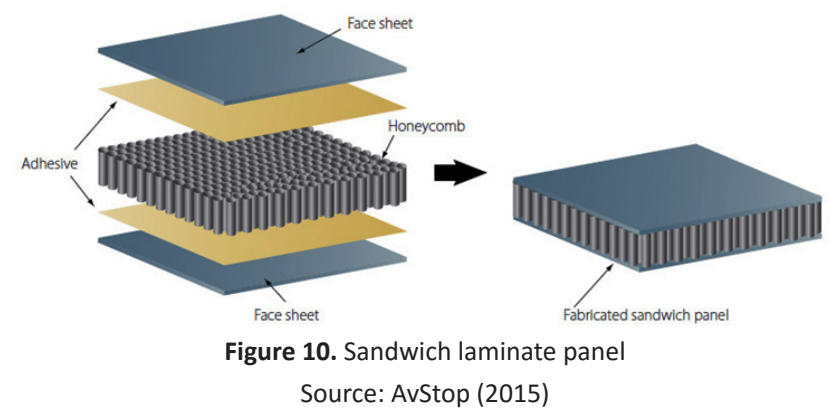

For this application a honeycomb made from nomex has been used for the tests.

\section{TESTS AND RESULTS}

The tests consist in milling trials of composite material and the comparison of two methods of tool entry, the Straight Plunge and Ramping-in. 
For both methods, the speed rate of the tool was 30 $\mathrm{mm} / \mathrm{s}$ and rotation at $15.000 \mathrm{rpm}$.

Straight plunge: This method is one that can easily break a tool or, in our case, increase the force in the joint 5 of the robot. The tool force is very high.

Figure 11 illustrates the Straight plunge entry.

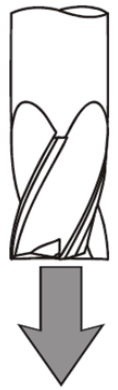

Figure 11. Straight plunge

Source: Helical Solutions (2015)

Ramping-in: This type of operation can be very successful. Finding a tool with good core strength plus room for proper chip evacuation is essential.

Some suggested starting ramp angles are described below:

- Non-Ferrous Materials: 3ㅇ - 10ㅇ․

- Ferrous Material: 1으 - 3ㅇ.

Figure 12 illustrates the Ramping-in entry.

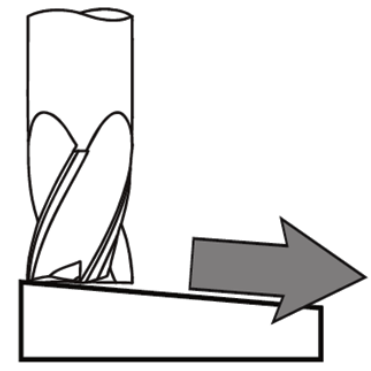

Figure 12. Ramping-in

Source: Helical Solutions (2015)

Some data from the robot was collect for the test using a functionality called record. This resource made possible to save many information about the robot when it moves as: commanded/feedback position of each motor and commanded/feedback current of each dive/motor current (A), which was used to identify the best strategy of entry and exit tool path.

The first identification on robot is visually showed below in Figure 13. It is possible to see a small movement against the entry toolpath in joint 5 of the robot.
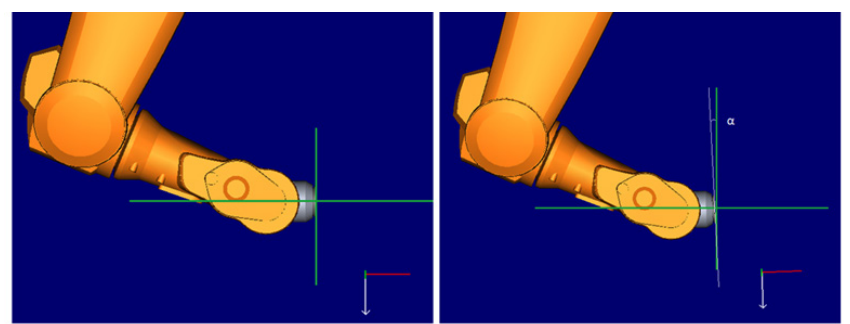

Figure 13. Representation of joint five being forced.

First step was to collect the information from the robot by performing the milling trajectory without a composite material. The robot moves free and these data are controlled. The graph of Figure 14 shows above the No Milling in gray.

Second step consists in doing the toolpath of milling on the composite material using as entry the Straight plunge. In the graph below is the data with the same name in orange colour.

Then, the last test was done using the Ramping-in method. The data with the same name in blue colour is showed in the graph of Figure 14.

All data were processed and analysed. For this proposal, only the data from the joint 5 of the robot was considered herein and there is no much difference related to other current motors.

Figure 14 represents the current (in Amperes) on joint 5 of robot.

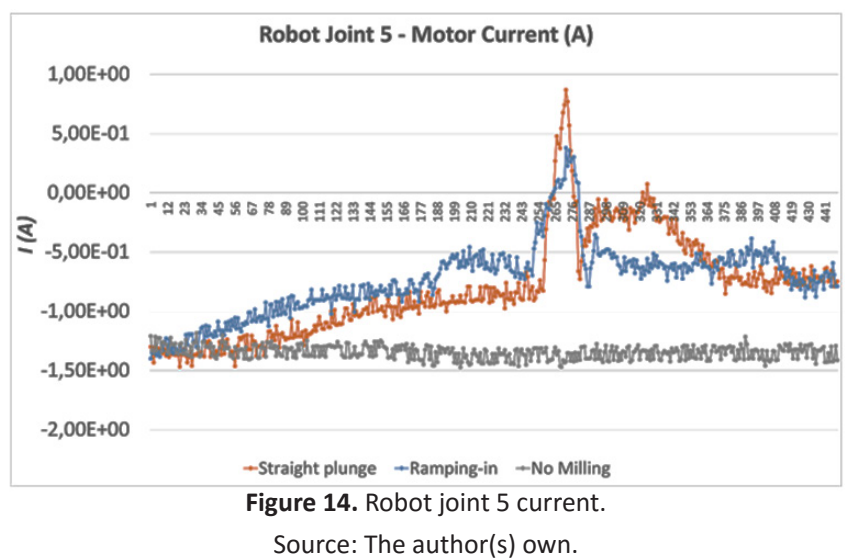

The graph compares the data of two strategies used for entry and exit of the tool in composite material during the milling process, the straight plunge and the ramping-in.

It has been collected about 450 data for the motor current information.

The gray line in the graph represents the control data that was collected at the robot controller, as stated earlier, without a milling trial of composite material.

The joint 5's motor current keeps in -1,43 A and the minus sign represents that the motor is running in counter-clockwise. 
For the Straight plunge, the orange line in the graph shows a peak of the joint 5's motor current exactly when the toll is entry in the composite material. At this moment of the tool entry in the composite material, the Straight plunge forces the motor on the joint 5 of the robot.

The motor is been forced against its direction of movement, the value of the current pass through the zero reference line and reaches $+0,868 \mathrm{~A}$, where as the current should be around $-0,893 \mathrm{~A}$.

Finally, the data of Ramping-in is the blue line in the graph.

Using the method, the effort on joint 5 was reduced to current of $+0,356 \mathrm{~A}$. The motor current still passed through the zero reference line but $56 \%$ less effort.

Thus, using the method of the Ramping-in, the effort has been reduced to $56.23 \%$.

\section{CONCLUSION}

Based on the results presented in this paper, it can be assured that the application of the correct method of tool entry contributes to more efficient manufacturing processes.

It means significantly costs' reduction of maintenance tasks on robot joint, energy savings and wastes related to damage of milling tools.

Also, where the Ramping-in method is used, it could increase the useful lifetime of the equipment due to reduce damages to the robot axes.

Thus, the evidences demonstrated that the application of the right strategy of the entry and exit of tool in plates of composite material is very important in order to adding value in terms of financial and technical issues.

Finally, it can be concluded that the Ramping-up method brings gains for milling process due to a significant force reduction in the joint 5 of the robot that increases the lifetime of the robot and avoid the tool from slipping.

As a suggestion of a future work, it would be interesting to study ( This part was not very clear, I added some information I think might be relevant)another machining strategy regarding the entry in rolling. (Helix) can be performed and tested.

\section{REFERENCES}

Aviation beta (2015). What materials make up most of the weight of an aircraft? http://aviation.stackexchange. com/questions/12958/what-materials-make-up-most-ofthe-weight-of-an-aircraft

AvStop (2015). Laminated Structures. Aviation Online Magazine. http://avstop.com/ac/Aviation Maintenance Technician_Handbook_General/5-34.html.
Controle e Automação Industrial (2014). Robôs: realidade e ficção. Resumo de aulas. http:// controleeautomacaoindustrial3.blogspot.com. br/2014_05_01_archive.html

D.M. Bushnell (2006). Industrial Design in Aerospace/ Role of Aesthetics. NASA Langley Research Center, TM-2006214498.

Electroimpact (2015). Overview of Electroimpact projects. https://www.electroimpact.com/.

F.R. Costa (2009). Current situation and perspectives of materials utilization in business aircraft. Master degree dissertation, Federal University of Sao Carlos, São Carlos.

G.F. Barbosa, E.C. Cordeiro, F.R. Costa (2015). Systems and Methods for Manufacturing Aircraft Furniture Parts Using an Integrated Automated Cell. SAE International Aerotech \& Congress. Paper 2015-01-2600.

H. Apmann, A. Hemmen, M. Herkt (2012). Automatic Handling of Carbon Fiber Preforms for CFRP Parts in Aerospace. SAE International. Paper 2012-01-1864.

Helical Solutions (2015). Cutting tools. https:// www.1helical.com.

M.K. Groover (2010). Fundamentals of Modern Manufacturing - Materials Processes and Systems. 4th edition. John Wiley \& Sons, Inc.

N.W. Sorbo, J.J. Dionne (2014). Dry Drilling of Stackup Composite: Benefits of $\mathrm{CO} 2$ Cooling. SAE International Journal of Aerospace. Volume 7, Issue 1.

R.E. Lyon (1997). Fire-Resistant Materials: Research Overview. Federal Aviation Administration, DOT/FAA/AR-9799.

S.T. Tsai (2008). Theory of Composites Design. In: Prasad,. Stanfor University.

Science in the News (2012). Carbon Fibre...a New Era in Aircraft Design? Posted by Mimi Ray. 